\title{
Methodology for Automatic Determination of Contrast of Laser Marking for Different Materials
}

\author{
Lyubomir Lazov \\ Faculty of Engineering \\ Rezekne Academy of Technologies \\ Rezekne, Latvia \\ llazov@abv.bg \\ Erika Teirumnieka \\ Faculty of Engineering \\ Rezekne Academy of Technologies \\ Rezekne, Latvia \\ erika.teirumnieka@rta.lv
}

\author{
Edmunds Teirumnieks \\ Faculty of Engineering \\ Rezekne Academy of Technologies \\ Rezekne, Latvia \\ edmunds.teirumnieks@rta.lv
}

\author{
Nikolay Angelov \\ Department of Physics, Chemistry and \\ Ecology \\ Technical University of Gabrovo \\ Gabrovo, Bulgaria \\ angelov_np@abv.bg
}

Abstract-A new methodology for determining and optimizing the contrast of the technological laser marking process has been developed. It can evaluate the quality of the markings regardless of the type of material and the type of laser system.

To perform the test analysis, a specialized test field is programmed, which including the change of two of the main parameters influencing the marking process: the linear energy density (LED) and the linear density of the pulses (LDI). Marking of a test field consisting of squares of a certain size is done by means of a raster marking method with a constant step between the lines.

The results are processed with a digital camera and specialized software. The maximum blackening is compared with the background of all fields and is juxtaposed with the effective energy needed to obtain a certain contrast. Several consecutive iterations are made, with each of the following experiments excluding the variants with least contrast. Thus, the study consistently brings the result to a minimum working area of the basic technological parameters, providing the user's desired contrast of the marking.

The developed author's method of automatically determining the contrast of the laser marking reduces the time for preliminary experimental research and gives a reliable and subjectively absent way of qualitatively marking different types of industrial products.

Keywords-method, laser marking, software, digital camera, contrast, linear energy density, linear density of the pulses.

\section{INTRODUCTION}

Laser marking is a technological process in which a number of mutual connected physical phenomena and effects participate, and with interaction of laser radiation with material. These processes are connected with each other in many cases, i.e. they interact with each other. In order to manage the qua-lity and the results of technology process, it is necessary to know these processes, as well as to know the principles connecting them. This knowledge is also necessary for successful monitoring of technological process in on-line regime and for selection of appropriate device for creating of technological systems. Laser processing occurs in space and time and represents an impact of radiation on the material. Therefore, there is a need to explore the quantity of absorbed energy of laser radiation in substrate and its impact on the material. Fig. 1 presents the principal scheme of energy balance of laser impact on metals and alloys. This gives us a notion of complexity of interaction of laser radiation with material and connections between these phenomena and processes.

As a result of interaction, electromagnetic energy is transformed in thermal energy. The efficiency of the entire process is strongly impacted by the losses that are a result of scattering and reflection

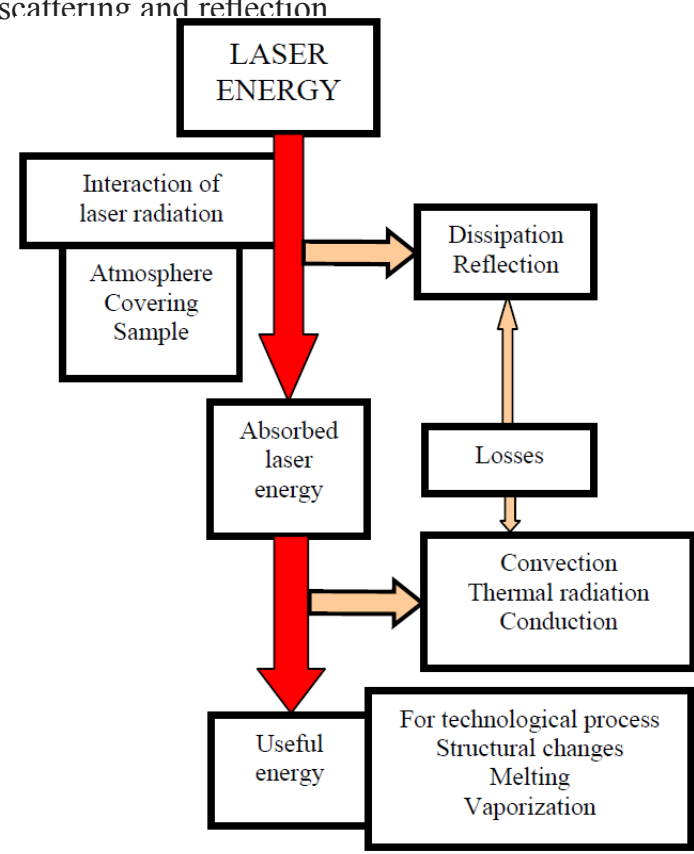

Fig. 1. Principal scheme of energy balance of laser impact Print ISSN 1691-5402

Online ISSN 2256-070X

http://dx.doi.org/10.17770/etr2019vol3.4143

(C) 2019 Lyubomir Lazov, Edmunds Teirumnieks, Nikolay Angelov, Erika Teirumnieka. Published by Rezekne Academy of Technologies.

This is an open access article under the Creative Commons Attribution 4.0 International License. 
Only actually absorbed quantity has a direct impact on the technology method and the result of the processing. It is clear that with regards to the technological method of melting, vaporizing or structural changes in the material, only a part of that energy makes a real contribution, because the losses appear as a result of convection, heat radiation and thermal conductivity.

We may examine the absorbed energy as a degree of efficiency $\eta_{\mathrm{A}}$ of total laser energy that falls onto the material, i.e. that is a part of falling energy which really participates in processing (structural changes, melting, vaporization in the unit volume).

In certain references it is defined as a percentage of the total energy falling onto the material, necessary

for concrete processing. Under certain simplifications, if we ignore the conditions of working zone (convection, heat radiation and thermal conductivity) we assume that it is energy absorbed by the material.

\section{EXPOSITION}

\section{A. Theoretical aspects}

Contrast is a key factor for determining laser marking quality [1-5]. There are several parameters that affect laser marking contrast. According to $[6,7]$ they can be grouped in the following way:

- Parameters related to laser source - surface density of laser radiation power $q_{\mathrm{S}}$, pulse energy $\mathrm{Ep}$, frequency of pulse repeating $v$, duration of pulses $\tau$;

- Parameters related to material properties - optical and thermo-physical characteristics;

- Parameters related to the manufacturing technology process - marking speed $v$, step $\Delta x$, number of repeatition $N$, defocusing $\Delta f$.

Other parameters include the coefficient of overlapping $k_{\text {ov }}$, a complex parameter which depends both on laser parameters and those of the manufacturing technology process $k_{\mathrm{ov}}=f(v, v, d)$, where $d$ is the diameter of the work spot.

A number of magnitudes influence the laser marking process of steels. Some of the magnitudes influencing the process are of a complex nature. As such, linear energy density, linear power density, linear pulse density, volumetric energy density, fill factor, and overlap coefficient, can be indicated.

Linear density of energy $E_{1}$ is a complex magnitude associated with laser parameters and technological parameters. Determined by the formula

$$
E_{1}=\frac{P}{v},
$$

where $P$ is the power of the falling laser radiation, $v$ - marking speed.

The magnitude of a linear energy density is numerically equal to the absorbed energy per unit length in the laser marking area.

Linear energy density should have a value that allows the material in the processing area to melt or evaporate. It is also decisive in order to obtain a good quality marking, respectively, with good contrast..

Linear pulse density $I_{I}$ is a complex magnitude associated with laser and technological parameters. It obtains from the expression

$$
l_{1}=\frac{v}{v}
$$

where $v$ is the frequency of following the pulses.

The magnitude of the linear density of the pulses is numerically equal to the number of impulses fallen to a unit length.

Effective energy $E_{e f}$ is a complex magnitude associated with laser parameters and technological parameters.

It is defining with the expression

$$
E_{e f}=E_{I} I_{r}
$$

The magnitude $E_{e f}$ gives the absorbed energy of the laser radiation per unit area of the laser impact area.

After replacing (1) and (2) in (3), it is obtained

$$
\mathrm{E}_{\mathrm{ef}}=\frac{P v}{v^{2}}
$$

What obtains in the zone of laser impact - heating, melting or evaporation depends on the energy that is absorbed in it.

\section{B. Methodology of experimental studies}

The implementation of the individual stages of the experimental research methodology can be described in the following example:

The laser marking process for steel CT80 is investigating. It is with widely using in the industry. It is used to make tools that work in conditions that do not cause cutting edge edges: milling cutters, countersinks, axes, chisels, chisels, longitudinal and disk saws, grooving rollers, kerners, screwdrivers, combined pliers, side cutters [8]. A laser technology system with a fiber laser is used to conduct the experiments $[9,10]$. The more important parameters of the system are given in Table I. The fiber laser emits in the near infrared area and operates in pulse mode. It has high beam quality and its pulse frequency changes over a wide diapason. The system has high positioning accuracy and good repeatability.

Table I. Basic Parameters Of Technological Systems With Cubr LASER AND FiBer LASER

\begin{tabular}{|l|c|}
\hline \multicolumn{1}{|c|}{ Parameter } & Value \\
\hline Wavelength $\lambda, \mu \mathrm{m}$ & 1,062 \\
\hline Power $P, \mathrm{~W}$ & 30,0 \\
\hline Frequency $\nu, \mathrm{kHz}$ & $10 \div 50$ \\
\hline Pulse duration $\tau, \mathrm{ns}$ & 250 \\
\hline Pulse energy $E_{\mathrm{p}}, \mathrm{mJ}$ & $0,60 \div 3,00$ \\
\hline Pulse power $P_{\mathrm{p}}, \mathrm{kW}$ & $2,40 \div 12,0$ \\
\hline Beam quality $M^{2}$ & $<1,1$ \\
\hline Positioning accuracy, $\mu \mathrm{m}$ & 2,5 \\
\hline Efficiency, $\%$ & 40 \\
\hline
\end{tabular}




\section{Stages}

- A test field consisting of squares with a side of $5 \mathrm{~mm}$, is compiled (Fig. 2);

A test field consisting of 100 squares with a side of 5 $\mathrm{mm}$ is realized, arranged in 10 rows and 10 columns.

- The intervals of change of the linear energy density and the linear density of the pulses are determined;

Based on our previous research on the laser laser marking process and formulas (1) and (2), preliminary intervals for the linear pulse density $l_{\perp}$ and the linear energy density $E_{1}$ are defined:

$I_{1} \in\left[3,33.10^{5} ; 7,83.10^{5}\right] \mathrm{m}^{-1}$ and

$E_{1} \in[183,333] \mathrm{J} / \mathrm{m}$.

- $\quad$ The squares are marking raster;

Through the laser technology system, the squares with different values of the linear density of impulses and the linear density of the energy are marked. A raster marking method is applied, with step $\Delta x$ being maintained constant $\Delta x=50 \mu \mathrm{m}$.

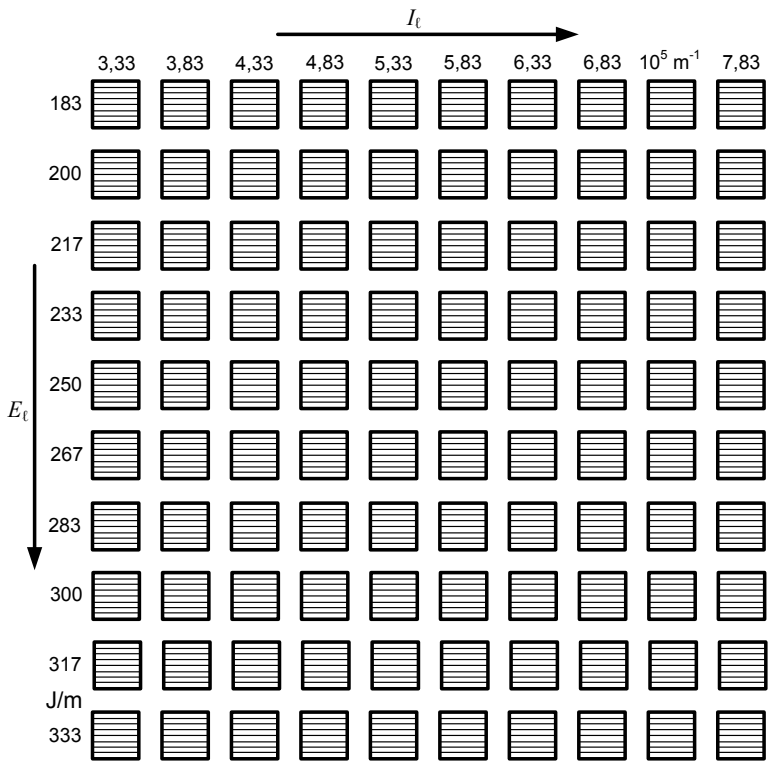

Fig. 2. Test field for conducting of the experiments

- The contrast of the marking are determined;

For measuring contrast $k^{*}$ a methodology was used prescribed by the Bulgarian State Standard 16383:1986.

Contrast $k^{*}$ is determined in percentage through a reference scale of grey color either in relative units or in percents. A black and white photo is made in the marking zone for the purpose of contrast measuring. By comparing the investigated image with the reference scale a value $N_{x}$ in the range between 0 (black) and 255 (white) is selected. A reference number $N_{f}$ is set for the background (that is the image on the surface around the marked zone). Contrast $k_{x}^{*}$ is defined by way of linear interpolation from the expression

$$
k_{x}{ }^{*}=\frac{N_{f}-N_{x}}{N_{f}} \cdot 100 \% \text {. }
$$

- Reducing the intervals of the studied magnitudes;
The obtained markings are investigated by determining the contrast of each square with a camera.

Fields with less contrast are excluded, and new experiments are performed by narrowing the investigated intervals for the linear energy density and the linear pulse density.

- The iterations are repeated until optimal contrast of the laser marking is achieved.

Working intervals of linear energy density and linear pulse density are determined.

\section{CONCLUSION}

The process of laser marking is the subject of research by a number of authors.

In recent years, laser marking of $1 \mathrm{D}$ and $2 \mathrm{D}$ barcodes on the products has increased considerably. The marking of this type is applied directly to the product. It allows to automate the process of reporting and controlling production, to protect the product from forgery. With laser technology for marking of barcodes achieve a high density of inflicted information. For this type of marking, it is particularly important to achieve an optimal contrast ratio relative to the basic background of the sample and the surface of the material.

The methodology proposed and considered by us will be useful for the operators of laser systems to reach the desired optimal technological parameters more quickly.

\section{REFERENCES}

[1] Velotti, C., A. Astarita, C. Leone, S. Genna, F. Minutolo, A. Squillace, Laser marking of titanium coating for aerospace applications, Procedia CIRP 41, 2016, pp. 975 - 980

[2] Sobotova, L. P. Demec, P. Laser marking of metal materials. Modern Machinery Science Journal, 2015, pp. 808-812.

[3] Valiulin A., Gorniy S., Grechco Y., Patrov M., Yudin K., Yurevich V. Lazerna markirovka materialov. Nauchno-technicheskij zhurnal Fotonika, 2007, 3, pp 16-22 (in Russian).

[4] Jianmei Li, Aiqun Wang, Yusong Wuab, ZhuoMa, Xinxin Fang, LiangTao, Experimental investigation and mathematical modeling of laser marking two-dimensional barcodes on surfaces of aluminum alloy, Journal of Manufacturing Processes, Volume 21, January 2016, pp 141-152.

[5] Han A., D. Gubencu, Analysis of the Laser Marking Technologies, Nonconventional Technologies Review, № 4, 2008, pp. 17-22.

[6] Lazov L., Angelov N. Vliyaniye na nyakoi faktori vyrhu procesa na lazerno markirane na izdeliya ot metali i splavi. mezhdunarodna nauchna konferenciya UNITEH`11. Gabrovo, 18-19 noembri 2011 (in Bulgarian)

[7] Angelov N. Optimizacija na procesa markirane s lazerno lychenie na obrazci ot instrumentalna stomana. Disertacionen trud za pridobivane na stepen doktor. TU-Gabrovo, 2011 (in Bulgarian)

[8] www.splav-kharkov.com/main.php

[9] www.axsys.de

[10] www.spilasers.com 